\title{
Phytoplankton sterol contents vary with temperature, phosphorus and silicate supply: a study on three freshwater species
}

\author{
MAIKE PIEPHO ${ }^{1}$, DOMINIK MARTIN-CREUZBURG ${ }^{2}$ AND ALEXANDER WACKER ${ }^{1}$ \\ ${ }^{1}$ Institute of Biochemistry and Biology, Theoretical Aquatic Ecology, University of Potsdam, Am Neuen Palais 10, \\ 14469 Potsdam, Germany \\ ${ }^{2}$ Limnological Institute, University of Constance, Mainaustr. 252, 78464 Konstanz, Germany
}

\begin{abstract}
The understanding of environmentally induced changes in the biochemical composition of phytoplankton species is of great importance in both physiological studies and ecological food web research. In extensive laboratory experiments we tested the influence of two different temperatures $\left(10^{\circ} \mathrm{C}\right.$ and $\left.25^{\circ} \mathrm{C}\right)$ and a phosphorus supply gradient on the sterol concentrations of the three freshwater phytoplankton species Scenedesmus quadricauda, Cryptomonas ovata and Cyclotella meneghiniana. The diatom C. meneghiniana was additionally exposed to a silicate gradient. In two separate experiments we analysed (1) possible interactive effects of temperature and phosphorus supply and (2) the effect of four phosphorus levels and three silicate levels on algal sterol concentrations. We observed that sterol concentrations were higher at $25^{\circ} \mathrm{C}$ than at $10^{\circ} \mathrm{C}$ in S. quadricauda and C. meneghiniana, but were not affected by temperature in C. ovata. Interactive effects of temperature and phosphorus supply on sterol concentrations were found in C. meneghiniana. This presumably was due to the bioconversion of one sterol (24-methylenecholesterol) into another (22-dihydrobrassicasterol). Increasing phosphorus supply resulted in species-specific effects on sterol concentrations, viz. an optimum curve response in $S$. quadricauda, a saturation curve response in C. meneghiniana and no change in sterol concentration in C. ovata. Effects of silicate supply on the sterols of C. meneghiniana equalled the effects of phosphorus supply. Albeit we did not observe a general trend in the three phytoplankton species tested, we conclude that sterol concentrations of phytoplankton are strongly affected by temperature and nutrient supply. Interactive effects point out the importance of taking into account more than just one environmental factor when assessing the effects of environmentally induced changes on phytoplankton sterol concentrations.
\end{abstract}

Key words: algae, Chlorophyta, Cryptomonas, Cryptophyta, Cyclotella, diatoms, phosphorus, Scenedesmus, silicate, sterols, temperature

\section{Introduction}

In eukaryotic cells, sterols are important membrane components that stabilize the structure of phospholipid bilayers and thus play a significant role in membrane temperature acclimation (Crockett, 1998; Rog et al., 2009). Temperature sensitivity of organisms is determined by their ability to maintain a certain membrane fluidity and permeability over a wide temperature range. The destabilization of membranes at high temperatures is potentially avoided by the incorporation of additional sterols into the phospholipid bilayer (Ford \& Barber, 1983). Moreover, in many organisms, sterols serve as important precursors for steroid hormones (Goad, 1981; Grieneisen, 1994;

Correspondence to: Maike Piepho. E-mail: piepho@unipotsdam.de
Martin-Creuzburg et al., 2007). Interestingly, higher plants and in particular algae contain a great number of different phytosterols, whereas animals predominantly contain cholesterol (Martin-Creuzburg \& von Elert, 2009a). In plants more than 200 different phytosterols have been reported (Hartmann, 1998; Moreau et al., 2002). However, this high diversity is not necessarily reflected in single species. Whereas in some algae a single sterol predominates, others possess mixtures of ten or more sterols (Volkman, 2003). From an evolutionary perspective, the reasons why plants and algae have maintained such a high diversity of sterols remain unclear and the physiological functions of the different phytosterols are only partially understood. As an example, Beck et al. (2007) analysed the role of phytosterols in temperature acclimation of higher 
plant cells and came to the conclusion that, compared with cholesterol, additional ethyl groups present in some phytosterols further decrease temperature sensitivity by reinforcing van der Waals interactions. However, it is also assumed that specific phytosterols have additional functions apart from their structural role in cell membranes. For example, Grandmougin-Ferjani et al. (1997) revealed that cholesterol and stigmasterol were able to stimulate the $\mathrm{H}+$ pump of the ATPase in higher plant plasma membranes. Furthermore, stigmasterol was less efficient in regulating membrane permeability than sitosterol and 24-methylcholesterol (Schuler et al., 1991). Both examples suggest that not all of the functions of the various phytosterols have yet been explored.

The sterol composition of phytoplankton is of special interest in the study of food webs and trophic interactions, because crustacean zooplankton, the primary consumers in aquatic ecosystems, depend on ingesting sterols with their diet (Martin-Creuzburg \& von Elert, 2009b; Lukas et al., 2011; Sperfeld et al., 2012). In addition to temperature, other factors significantly affect the sterol composition and concentration in algae and hence possibly also the availability of sterols for higher trophic levels. In a previous study, we showed that the sterol concentrations of four common phytoplankton species changed significantly with increasing light intensity and that the reaction to light was influenced by phosphorus availability (Piepho et al., 2010). The results suggested that with high light intensities and a low phosphorus supply, which represents a common scenario in many lakes during summer, the sterol concentrations of algae are reduced. Thus, sterol limitation of crustacean consumers appears most likely during summer. The variation of sterols with light and phosphorus supply also implies that a change in sterol concentration may have other advantages, besides regulation of temperature sensitivity, in adaptation to varying environmental conditions. What these functions are and how they are regulated remains to be investigated. The analysis of changes in sterol content with external conditions, such as light, temperature or nutrient availability, is necessary to understand the biochemical composition of phytoplankton and to assess its consequences for consumers in the aquatic food web.

Although the role of sterols in temperature adaptation has often been described, interactive effects of temperature and other environmental conditions have been neglected. In this study, we analysed how temperature influences the sterol concentration in three common freshwater phytoplankton species in low- and high-phosphorus conditions. In addition, we tested the change of sterol concentrations across a gradient of four phosphorus levels in the culture media. Diatoms, which often form a major part of the phytoplankton community, depend on silicate to form their frustules. Therefore, we also tested the influence of three silicate levels on the sterol concentration of the diatom Cyclotella meneghiniana.

\section{Materials and methods}

\section{Cultures}

The green alga Scenedesmus quadricauda, the cryptophyte Cryptomonas ovata (both species from the culture collection of the Limnological Institute, University of Constance), and the diatom Cyclotella meneghiniana (collection of algal cultures, Göttingen, Germany, SAG 1020-1a) were cultivated in WC-medium (Nichols, 1973), using different phosphorus concentrations and temperatures. We used semi-continuous culture conditions, i.e. diluted the cultures every day at the same time. In order to avoid daily fluctuations and short-term adaptations in the biochemical composition of the algal cells, we applied continuous lighting $\left(200 \mu \mathrm{mol}\right.$ PAR photons $\left.\mathrm{m}^{-2} \mathrm{~s}^{-1}\right)$. Different growth in high-P and low-P treatments could potentially result in different cell densities and thus different shading inside the cultures. To avoid such variation, the cultures were diluted every day to the same optical density (OD: 0.05 , 800 nm; Shimadzu, Duisburg, Germany, UV mini-1240). This led unavoidably to varying dilution rates. Carbon deficiency was avoided by aerating the media with sterile-filtered air. Cultures were grown for 10-20 days until the growth rate remained constant and the cells were adapted to the experimental conditions. Growth rates were calculated as follows:

$$
\mu=\left[\ln \left(\mathrm{OD}_{2}\right)-\ln \left(\mathrm{OD}_{1}\right)\right] / t
$$

where $\mu$ is the growth rate, $\mathrm{OD}_{1}$ is the initial optical density at $800 \mathrm{~nm}$, and $\mathrm{OD}_{2}$ is the optical density at $800 \mathrm{~nm}$ after time $t$.

\section{Temperature levels}

In the temperature experiment, the species were each grown in a high-P $(50 \mu \mathrm{M} \mathrm{P}$, provided in the form of $\mathrm{K}_{2} \mathrm{HPO}_{4}$ ) and a low-P medium at $10^{\circ} \mathrm{C}$ and at $25^{\circ} \mathrm{C}$. The low-P medium was $1 \mu \mathrm{M}$ P for Scenedesmus, $5 \mu \mathrm{M}$ P for Cryptomonas and $2.5 \mu \mathrm{M} \mathrm{P}$ for Cyclotella because of species-specific differences in their optimum phosphorus requirements (Rhee, 1978; Klausmeier et al., 2004). Experimentally reduced $\mathrm{K}_{2} \mathrm{HPO}_{4}$ concentrations were counterbalanced by the addition of $\mathrm{KCl}$ to the growth medium to avoid K-limitation. We chose $10^{\circ} \mathrm{C}$ and $25^{\circ} \mathrm{C}$ to represent two extreme temperatures that potentially occur during the growth season in the euphotic zone of temperate lakes (Mitchell et al., 2004), depending on depth and latitudinal position (Mitchell \& Lampert, 2000). The species were each cultured in $500 \mathrm{ml}$ of the respective medium in 1-litre Erlenmeyer flasks $(n=3)$. 


\section{Phosphorus and silicate gradients}

In the phosphorus experiment, a phosphorus gradient (at $20^{\circ} \mathrm{C}$ ) was achieved by applying four different phosphorus concentrations in the culture media. The concentrations were 1, 5, 10 and $50 \mu \mathrm{M}$ P for Scenedesmus, 5, 10, 20 and $50 \mu \mathrm{M}$ P for Cryptomonas, and 2.5, 5, 10 and $50 \mu \mathrm{M} \mathrm{P}$ for Cyclotella. Omitted $\mathrm{K}_{2} \mathrm{HPO}_{4}$ was substituted by $\mathrm{KCl}$. Cultures were grown in 1-litre Erlenmeyer flasks, each in $500 \mathrm{ml}$ of the respective medium, with three replicates per treatment. In addition, Cyclotella was grown in a silicate gradient of 50, 100 and $200 \mu \mathrm{M} \mathrm{Si}$. The nutrient gradients were chosen based on preliminary experiments that showed that $50 \mu \mathrm{M}$ P represents a phosphorus-replete condition while the lowest P-concentrations for each species constitute P-limited conditions under which growth is only just possible (our unpublished data).

\section{Sterol analyses}

Samples for sterol determination were obtained by filtering $0.5-1 \mathrm{mg}$ algal carbon on 25-mm glass fibre filters (Whatman, GF/F). Filters were stored at $-25^{\circ} \mathrm{C}$ under a nitrogen atmosphere in glass tubes with a Teflon seal, after adding $7 \mathrm{ml}$ of dichlormethane-methanol $(2: 1 \mathrm{v} / \mathrm{v})$. Extraction of lipids was done twice with dichlormethane-methanol (2:1 v/v; cf. Cequier-Sánchez et al., 2008). We omitted a treatment with hot isopropanol because preliminary studies showed that this treatment would not improve lipid extraction (Supplementary Figure S1). Before further analysis, a defined concentration of $5 \alpha$-cholestane (Sigma-Aldrich, R205370-1EA) was added as an internal standard (IS). The extracted and dried lipid sample was saponified with $4 \mathrm{ml}$ $0.2 \mathrm{moll}^{-1}$ methanolic $\mathrm{KOH}\left(60 \mathrm{~min}\right.$ at $\left.70^{\circ} \mathrm{C}\right)$. After addition of $1 \mathrm{ml}$ ultra-pure water, neutral lipids (including sterols) were partitioned into isohexane/diethyl ether $(9: 1 \mathrm{v} / \mathrm{v})$. This fraction was evaporated to dryness under nitrogen gas and resuspended in isohexane (see also Wacker \& Martin-Creuzburg, 2007). After extraction of lipids, identification and quantification of sterols was done by gas chromatography (GC, Agilent Technologies, 6890 N) according to Wacker \& MartinCreuzburg (2007), but according to the following protocol: $1 \mu \mathrm{l}$ of sample was injected in split mode $(5: 1)$, vaporized in the injector at $350^{\circ} \mathrm{C}$ and mixed with the carrier gas (helium). Sterols were separated by a polysiloxane column (Agilent technologies J\&W HP-5, $30 \mathrm{~m} \times 0.32 \mathrm{~mm} \times 0.25 \mu \mathrm{m})$, using the following temperature gradient: $150^{\circ} \mathrm{C}$ for $1 \mathrm{~min}, 15^{\circ} \mathrm{C} \mathrm{min}^{-1}$ until $280^{\circ} \mathrm{C}$, $2^{\circ} \mathrm{C} \mathrm{min}^{-1}$ until $308^{\circ} \mathrm{C}, 10^{\circ} \mathrm{C} \mathrm{min}^{-1}$ until $320^{\circ} \mathrm{C}$. Sterols were detected using a flame ionization detector (FID) at $350^{\circ} \mathrm{C}$ and quantified by comparison to IS and by using multipoint standard calibration curves determined for each sterol from mixtures of known composition. Sterols were identified via retention times and their mass spectra, which were recorded with a gas chromatograph-mass spectrometer (Agilent Technologies, 5975 C) equipped with a fused-silica capillary column (Agilent Technologies, DB-5MS; see Martin-Creuzburg et al., 2009). Sterols were analysed in their free form and as their trimethylsilyl derivatives, which were prepared by incubating $20 \mathrm{ml}$ of isohexane sterol extract with $10 \mathrm{ml}$ of N,O-bis(trimethylsilyl)trifluoroacetamide including $1 \%$ trimethylchlorosilane for $1 \mathrm{~h}$ at room temperature. Spectra were recorded between 50 and $600 \mathrm{amu}$ in the EI ionization mode. The limit of sterol quantification was $20 \mathrm{ng}$. The C-24 stereochemistry and the cis-trans isomery of sterols could not be identified with certainty and thus, if procurable, was adopted from the literature (see also Piepho et al., 2010). Accordingly, since it has been reported that cryptophycean algae contain epibrassicasterol (IUPAC name: (22E)campesta-5,22-dien-3 $\beta$-ol), which is the $24 \alpha$-epimer of brassicasterol ((22E)-ergosta-5,22-dien3 $\beta$-ol) (Goad et al., 1983; Gladu et al., 1990), the presence of epibrassicasterol rather than brassicasterol was assumed in $C$. ovata. The two sterols, 24-methylenecholesterol (ergosta-5,24(24 $)$-dien-3 $\beta$-ol) and 22-dihydrobrassicasterol (ergost-5-en-3 $\beta$-ol), detected in $C$. meneghiniana, could not be sufficiently separated by GC-FID and thus the relative contribution of each sterol was estimated by comparing ion-pair ratios (i.e. analyte: IS ratios), using selected ion monitoring (SIM).

\section{POC determination}

Particulate organic carbon (POC) was measured by first filtering $\sim 0.25 \mu \mathrm{g}$ carbon of the algal suspension onto precombusted glass fibre filters (Whatman, $\mathrm{GF} / \mathrm{F}$, $25 \mathrm{~mm}$ ) and then quantifying algal $\mathrm{C}$ using an elemental analyser (HEKAtech GmbH, Wegberg, Germany, Euro EA 3000).

\section{Statistics}

Sterol concentrations of algae were expressed on a per carbon basis and differences between phosphorus levels were analysed by one-way ANOVA and Tukey tests. To analyse interactive effects of P-availability and temperature on the sterol concentration we used a two-way ANOVA, with temperature and medium phosphorus concentration as independent factors. All statistical calculations were carried out using the statistical software package $\mathrm{R}$, which is under general public licence ( $R$ Development Core Team, version 2.6.0, 2007). The level of significance was set at $\mathrm{P}<0.05$.

\section{Results}

\section{Temperature levels}

In each of the three analysed phytoplankton species sterol concentrations responded differently to the temperature levels. In $S$. quadricauda we detected fungisterol ( $5 \alpha$-ergost-7-en- $3 \beta$-ol), chondrillasterol ((22E)-5 $\alpha$-poriferasta-7,22-dien-3 $\beta$-ol) and 22-dihydrochondrillasterol ( $5 \alpha$-poriferast7 -en-3 $\beta$-ol). All three sterols increased in concentration from the $10^{\circ} \mathrm{C}$ to the $25^{\circ} \mathrm{C}$ treatment $(\mathrm{P}<0.01$; Fig. 1), and did not differ between the high-P and the low-P treatments.

In contrast to $S$. quadricauda, we observed no significant change in the concentration of the 

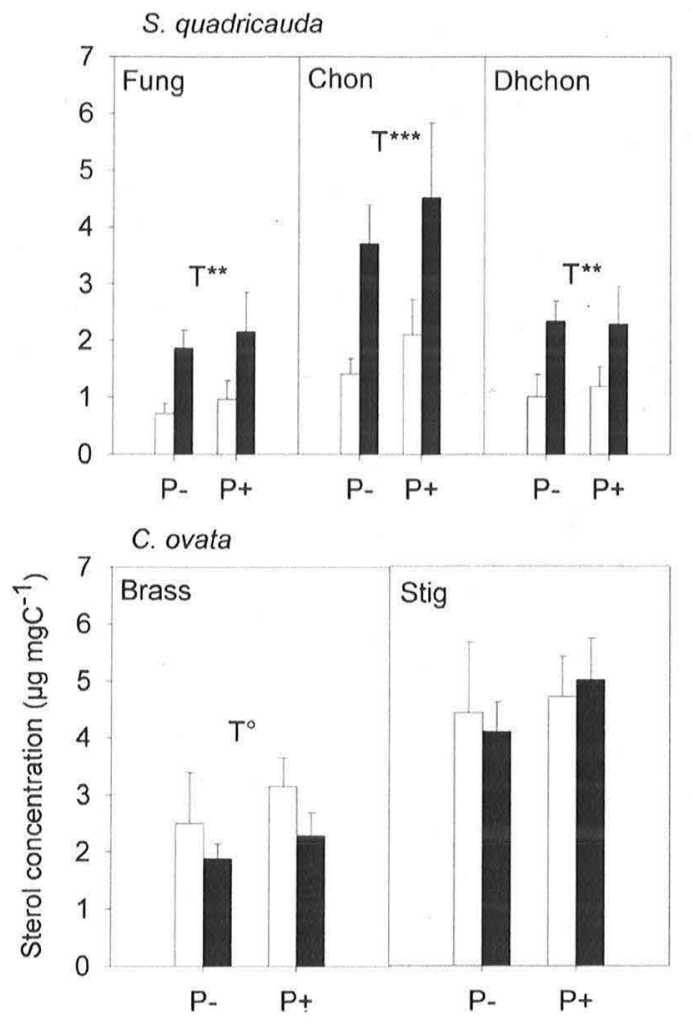

C. meneghiniana

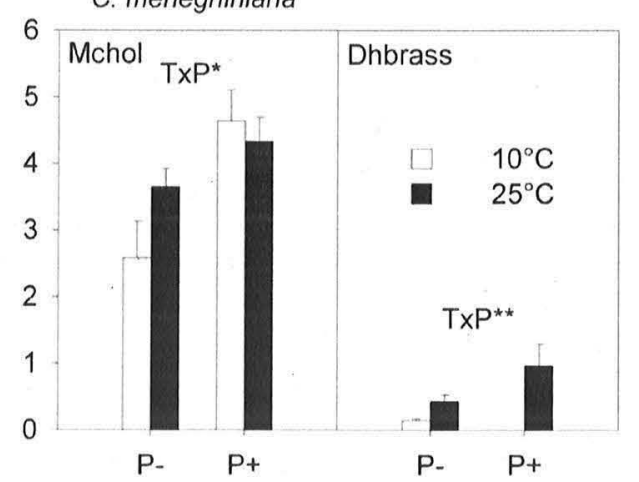

Fig. 1. Sterol concentrations of $S$. quadricauda, C. ovata and $C$. meneghiniana at $10^{\circ} \mathrm{C}$ and $25^{\circ} \mathrm{C}$ each at low- $\mathrm{P}(\mathrm{P}-)$ and high-P supply $(\mathrm{P}+)$. Data shown are means and standard deviations. Significant effects of the two-way ANOVA: temperature $(\mathrm{T})$, phosphorus $(\mathrm{P})$, interaction $(\mathrm{T} \times \mathrm{P}): \quad{ }^{\circ} \mathrm{P}<0.1, \quad * \mathrm{P}<0.05, \quad * * \mathrm{P}<0.01, \quad * * * \mathrm{P}<0.001$. Fungisterol (Fung), chondrillasterol (Chon), 22-dihydrochondrillasterol (Dhchon), (epi)brassicasterol (Brass), stigmasterol (Stig), 24-methylenecholesterol (Mchol), 22-dihydrobrassicasterol (Dhbrass).

sterols of C. ovata (i.e. (epi)brassicasterol and stigmasterol ((22E)-stigmasta-5,22-dien-dien-3 $\beta$-ol) with increasing temperature and/or P-availability. Nevertheless, a trend of slightly higher concentrations of (epi)brassicasterol appears in the $10^{\circ} \mathrm{C}$ treatment compared with the $25^{\circ} \mathrm{C}$ treatment $(\mathrm{P}=0.052$, Fig. 1).

In C. meneghiniana, we detected 24-methylenecholesterol, low amounts of 22-dihydrobrassicasterol $\left(<1 \mu \mathrm{gmg} \mathrm{C}^{-1}\right.$, Figs 1, 2), and traces of
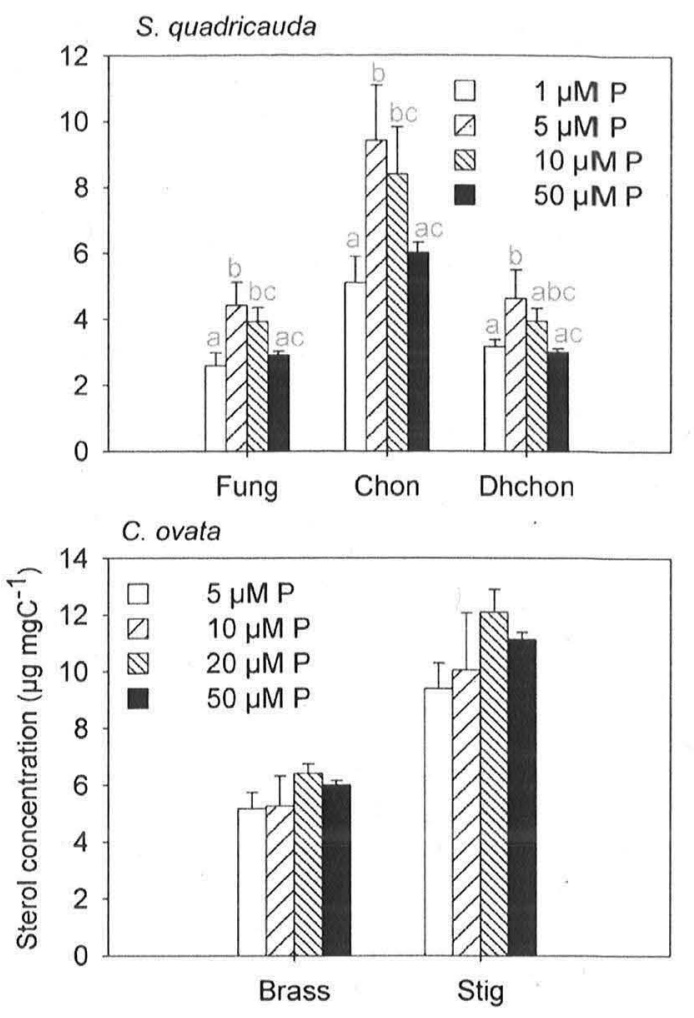

C. meneghiniana

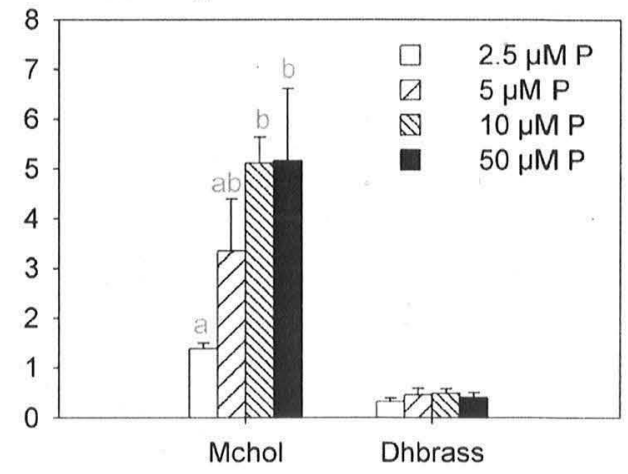

Fig. 2. Sterol concentrations of $S$. quadricauda, C. ovata and $C$. meneghiniana at different phosphorus supply levels. Data shown are means and standard deviations. Different letters indicate significant differences of means (post-hoc test, $\mathrm{P}<0.05$ ). Fungisterol (Fung), chondrillasterol (Chon), 22-dihydrochondrillasterol (Dhchon), (epi)brassicasterol (Brass), stigmasterol (Stig), 24-methylenecholesterol (Mchol), 22-dihydrobrassicasterol (Dhbrass).

desmosterol (cholesta-5,24-dien-3 $\beta$-ol). Statistical analysis revealed interactive effects of temperature and P-supply on the concentration of 24-methylenecholesterol and 22-dihydrobrassicasterol in $C$. meneghiniana. The concentration of 24-methylenecholesterol increased from low to high temperature in the low-P treatment but did not change with temperature in the high- $\mathrm{P}$ treatment $(\mathrm{P}<0.05$; Fig. 1). At $10^{\circ} \mathrm{C}, 22$-dihydrobrassicasterol was detected in the low-P treatment only. In both $\mathrm{P}$ treatments, 22-dihydrobrassicasterol increased 
from $10^{\circ} \mathrm{C}$ to $25^{\circ} \mathrm{C}$ but with a significantly more pronounced increase at high-P (interaction; $\mathrm{P}<0.01)$.

\section{Phosphorus and silicate gradients}

Increasing phosphorus supply resulted in speciesspecific different responses of sterol concentrations. In $S$. quadricauda we found an optimum curve response for all three sterols, fungisterol, chondrillasterol and 22-dihydrochondrillasterol, i.e. sterol concentrations were significantly higher at intermediate phosphorus supply levels than at low or high phosphorus levels $(\mathrm{P}<0.05$; Fig. 2). Fungisterol and chondrillasterol concentrations were both higher in the $5 \mu \mathrm{M}$ P and in the $10 \mu \mathrm{M}$ $\mathrm{P}$ treatments than in the $1 \mu \mathrm{M} \mathrm{P}$ and the $50 \mu \mathrm{M}$ $P$ treatments. We did not find any differences between the two extremes, i.e. $1 \mu \mathrm{M} \quad \mathrm{P}$ and $50 \mu \mathrm{M}$ P. The latter was also true for 22-dihydrochondrillasterol. The concentration of 22-dihydrochondrillasterol was highest in the $5 \mu \mathrm{M} \mathrm{P}$ treatment, whereas the $10 \mu \mathrm{M} \mathrm{P}$ and the $50 \mu \mathrm{M} \mathrm{P}$ treatments showed no significant difference from the $1 \mu \mathrm{M}$ P treatment (Fig. 2).

In contrast to $S$. quadricauda, in $C$. ovata we detected no significant change in sterol concentrations of (epi)brassicasterol and stigmasterol along the phosphorus gradient (Fig. 2). There was, however, a slight indication of an optimum response for stigmasterol, with stigmasterol concentrations increasing from the $5 \mu \mathrm{M}$ to the $20 \mu \mathrm{M}$ P treatment $(\mathrm{P}=0.09)$ but decreasing again at $50 \mu \mathrm{M} \mathrm{P}$.

The two sterols of $C$. meneghiniana responded differently to increasing phosphorus or silicate supply. Whereas the concentration of 22-dihydrobrassicasterol did not differ between the four $\mathrm{P}$ treatments and the three Si treatments, 24-methylenecholesterol concentration followed a saturation curve with increasing phosphorus (Fig. 2) or increasing silicate supply (Fig. 3). 24-methylenecholesterol increased from the $2.5 \mu \mathrm{M} \mathrm{P}$ to the $10 \mu \mathrm{M}$ and $50 \mu \mathrm{M} \mathrm{P}$ treatments $(\mathrm{P}<0.01)$, whereas the latter two treatments did not differ significantly (Fig. 2). We also found an increase of 24-methylenecholesterol from the $50 \mu \mathrm{M}$ Si to the $100 \mu \mathrm{M}$ and $200 \mu \mathrm{M}$ Si treatments $(\mathrm{P}<0.01)$. The two higher Si-treatments, i.e. $100 \mu \mathrm{M}$ Si and $200 \mu \mathrm{M} \mathrm{Si}$, were not significantly different (Fig. 3).

\section{Discussion}

Sterol concentrations varied with temperature, phosphorus and silicate supply in the three phytoplankton species, but the species exhibited different responses. However, Scenedesmus quadricauda and Cyclotella meneghiniana were similar in containing higher total sterol concentrations at $25^{\circ} \mathrm{C}$ than at

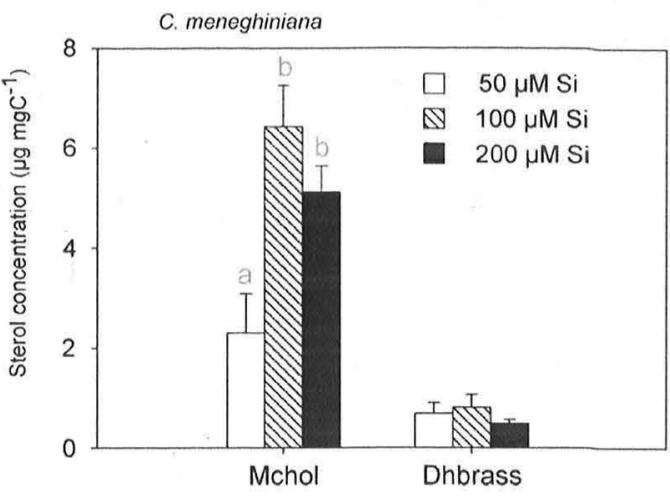

Fig. 3. Sterol concentration of C. meneghiniana at different silicate supply levels. Data shown are means and standard deviations. Different letters indicate significant differences of means (post-hoc test, $\mathrm{P}<0.05$ ). 24-methylenecholesterol (Mchol), 22-dihydrobrassicasterol (Dhbrass).

$10^{\circ} \mathrm{C}$, which adds to previous reports suggesting that sterols play an important role in maintaining the stability of plasma membranes at high temperatures (Ford \& Barber, 1983). In C. meneghiniana, 22-dihydrobrassicasterol was just detectable at $10^{\circ} \mathrm{C}$ but clearly detectable at $25^{\circ} \mathrm{C}$. This might indicate a specific role of this sterol in the adaptation to high temperatures. The incorporation of further sterol molecules into phospholipid bilayers at $25^{\circ} \mathrm{C}$ compared with $10^{\circ} \mathrm{C}$ would explain the increase in sterol concentration in $S$. quadricauda and $C$. meneghiniana with increasing temperature.

In contrast to the total sterol content of $C$. meneghiniana, which increased from low to high temperature and was higher in the high-P treatment than in the low-P treatment, for individual sterols we observed interactive effects of temperature and phosphorus supply. The two sterols found in C. meneghiniana - 24-methylenecholesterol and 22-dihydrobrassicasterol - belong to the same biosynthetic pathway, which is known from higher plants: 24-methylenecholesterol is a direct precursor of 22-dihydrobrassicasterol and differs only in an additional double bond at $\mathrm{C} 24$ that is reduced by a C24-reductase (Hartmann, 2004). The interactive effect of P-supply and temperature that we detected was potentially based on a higher activity of the reductase at high $\mathrm{P}$ supply and $25^{\circ} \mathrm{C}$ and might result in the higher concentration of 22-dihydrobrassicasterol compared to the treatment at low $\mathrm{P}$ supply and $25^{\circ} \mathrm{C}$. This may also explain why we did not observe an increase of 24 -methylenecholesterol from $10^{\circ} \mathrm{C}$ to $25^{\circ} \mathrm{C}$ in the high-P treatment.

We found no evidence for a role of sterols in temperature adaptation in $C$. ovata. The sterol composition of this alga appeared to be hardly affected by environmental conditions (see also Piepho et al., 2010), either temperature or 
phosphorus level. This might be due to the mixotrophic lifestyle of this alga (Tranvik et al., 1989) and associated differences in the adaptation response to changing environmental conditions as compared with exclusively phototrophic species. In order to sustain high photosynthetic rates, phototrophic organisms have to maintain a certain fluidity of chloroplast membranes, which ensures electron flow between the electron acceptors of photosystem II (Horváth et al., 1987; Mock \& Kroon, 2002). Although thylakoid membranes presumably do not contain sterols (Havaux, 1998), chloroplast envelope membranes contain low but significant amounts of sterols (Douce \& Joyard, 1990). Instead of maintaining the function of the photosynthetic apparatus by changing the biochemical composition of chloroplast membranes, C. ovata might switch to heterotrophy at unfavourable conditions. This could explain why we did not observe changing sterol concentrations in $C$. ovata with changing temperature or phosphorus supply. A comparison of adaptation in the sterol contents of phototrophic and several mixotrophic species grown under both heterotrophic and autotrophic conditions might clarify if our hypothesis is correct.

Increasing nutrient levels in the culture medium revealed that, in S. quadricauda and C. meneghiniana, the concentration of the most abundant sterol was lowest in the treatment with the lowest nutrient concentration, i.e. either phosphorus or silicate. The same trend was observed for stigmasterol in C. ovata, although there were no significant differences between phosphorus levels in this species. Most sterols that did not change with experimental conditions accounted for a minor proportion of total sterols. Therefore, the total sterol content, i.e. the sum of all sterols found in one species, was low when phosphorus or silicate supply in the medium was low. A comparable decrease in total sterol concentration was observed by Gordillo et al. (2001) in the nitrogen-limited macroalga Ulva rigida, compared with a nitrogensufficient treatment. Thus, an experimentally induced limitation of aquatic primary producers by phosphorus, silicate and nitrogen consistently results in the same response - a decrease in total sterol concentrations - which suggests that nutrient limitation in general impairs the synthesis of sterols in algae. Whether this is a direct effect, e.g. a suppression of enzymes involved in sterol synthesis, or an indirect effect, e.g. a reduced formation of plasma membranes in which sterols can be incorporated, remains to be tested. Moreover, in higher plants, enzymes involved in sterol synthesis are associated with membranes (Hartmann, 1998) and thus their function might indirectly depend on the building of plasma membranes.
We did not find a linear correlation between sterol concentrations and nutrient supply. Rather, there seemed to be a species-specific optimum of nutrient supply below which sterol concentrations decreased. Our data also showed that the concentrations of some sterols, such as those in S. quadricauda, decreased again in the treatment with the highest phosphorus concentration. This could have been caused by another nutrient imbalance that reduced sterol synthesis when phosphorus was in excess. Alternatively, an increase in carbon-rich components in the algae, due to favourable growth conditions at higher phosphorus supply, might have 'diluted' the algal sterols, which might explain why we found lower sterol concentrations per carbon in the treatment with the highest nutrient supply. Many data contradict this hypothesis, however, since it is generally found that carbon storage increases at low nutrient supply, when cell division rates decrease and less carbon is needed for the synthesis of new membrane components (Guschina \& Harwood, 2009).

In contrast to the optimum curve response in S. quadricauda, 24-methylenecholesterol of C. meneghiniana displayed a saturation curve as a response to increasing phosphorus or silicate levels. This may indicate that the diatom was able to maintain a constant sterol concentration over a broader range of nutrient conditions than the green alga. At high nutrient concentrations diatoms grow most efficiently (Egge \& Aksnes, 1992; Egge, 1998), which might be the reason why their biochemical composition was most stable under such conditions. Against this background, one could argue that $C$. ovata maintained homeostatic sterol concentrations over an even broader range of nutrient conditions. Preliminary experiments have revealed that this species is unable to grow in media containing less than the $5 \mu \mathrm{M} \mathrm{P}$ applied here (our unpublished data). This means that the sterol concentration of $C$. ovata was constant over varying phosphorus supply, even at growth-limiting conditions. The results showed that species belonging to different phyla differ greatly in their homeostatic regulation of sterol concentrations. Possible advantages or disadvantages for the algal cells of maintaining a constant sterol composition remain to be investigated.

The lowest and the highest phosphorus level to which each species was exposed here correspond to the low-P and the high-P treatments in our earlier study (Piepho et al., 2010). Our new results confirm the effects of phosphorus found in the previous study. For example, at intermediate light intensities, such as were used in the present experiment, the previous study showed no differences in sterol concentration between the low-P and the high-P treatment of $S$. quadricauda. Likewise, in the 
present study, we did not find a significant difference between sterol concentrations of the lowest and the highest phosphorus concentration. However, in the earlier study, we found distinct differences in sterol concentrations between low-P and high-P treatments of $S$. quadricauda in very low or very high light intensities. More precisely, sterol concentrations were higher in the high-P treatments than in the low-P treatments at high light intensities but lower in the high-P treatments than in the low-P treatments at low light intensities. Therefore, we assume that, because of the interactive effects of light intensity and phosphorus supply, the response in sterol concentrations with increasing phosphorus supply levels may change also with light intensity. At higher irradiances, e.g. $500 \mu \mathrm{mol}$ PAR photons $\mathrm{m}^{-2} \mathrm{~s}^{-1}$, we would expect a significantly higher sterol concentration in the highest phosphorus level than in the lowest phosphorus level in S. quadricauda.

We show here that environmental factors have interdependent influence on the sterol concentrations of phytoplankton. We found interactive effects of temperature and phosphorus supply (the present study) as well as of light and phosphorus supply (Piepho et al., 2010). Thus, the effect of one of these environmental factors should not be described without the other and the analysis of interactions of various environmental factors is a very important approach in understanding the changes of sterol concentrations in phytoplankton.

In the food web of aquatic ecosystems, primary consumers, such as Daphnia, depend on ingesting sterols as cholesterol precursors with their diet (Martin-Creuzburg \& von Elert, 2009b; Lukas et al., 2011; Sperfeld et al., 2012). In our former study (Piepho et al., 2010) we noted that a sterol limitation of herbivorous zooplankton is most likely in summer, because high light intensities and low phosphorus supply decrease sterol concentrations of algae, whereas the demand of Daphnia for sterols may increase with temperature (Sperfeld \& Wacker, 2009). The present study shows that high summer temperatures can increase sterol concentrations in some phytoplankton species and therefore might compensate for the higher sterol demand of primary consumers during this time of the year. Furthermore, we show that sterol concentrations of phytoplankton are reduced at low phosphorus or silicate supply levels, whereas medium phosphorus or silicate supply had no, or even a positive effect on sterol concentrations. Moreover, we found in one species that sterol concentrations per unit of carbon potentially decrease again at high phosphorus supply. Hence, the occurrence and strength of a sterol limitation of herbivorous zooplankton in lakes probably depends on many factors, primarily on the phytoplankton species composition but also on phytoplankton growth conditions, viz. elemental nutrient supply, temperature and light intensity. Our data emphasize the importance of accounting for all these factors when dealing with sterol limitation of herbivores in both laboratory and field studies.

\section{Acknowledgements}

We thank Silvia Heim and Viola Bittschier for assistance in experimentation and analysis and two anonymous reviewers, who helped to improve the manuscript. This study was supported by the German Research Foundation (DFG WA 2445/4-1).

Supplementary Figure S1. Sterol concentrations of Scenedesmus after use of 4 different lipid extraction methods.

\section{References}

Beck, J.G., Mathieu, D., Loudet, C., Buchoux, S. \& Dufourc, E.J. (2007). Plant sterols in "rafts": a better way to regulate membrane thermal shocks. FASEB Journal, 21: 1714-1723.

Cequier-Sánchez, E., Rodríguez, C., Ravelo, Á.G. \& Zárate, R. (2008). Dichloromethane as a solvent for lipid extraction and assessment of lipid classes and fatty acids from samples of different natures. Journal of Agricultural and Food Chemistry, 56: 4297-4303.

Crockett, E.L. (1998). Cholesterol function in plasma membranes from ectotherms: membrane-specific roles in adaptation to temperature. American Zoologist, 38: 291-304.

Douce, R. \& Joyard, J. (1990). Biochemistry and function of the plastid envelope. Annual Review of Cell Biology, 6: 173-216.

EgGe, J.K. (1998). Are diatoms poor competitors at low phosphate concentrations? Journal of Marine Systems, 16: 191-198.

EGGE, J.K. \& AKsnes, D.L. (1992). Silicate as regulating nutrient in phytoplankton competition. Marine Ecology Progress Series, 83: 281-289.

ForD, R.C. \& BARBER, J. (1983). Incorporation of sterol into chloroplast thylakoid membranes and its effect on fluidity and function. Planta, 158: 35-41.

Gladu, P.K., Patterson, G.W., Wikfors, G.H., Chitwood, D.J. \& LusBY, W.R. (1990). The occurrence of brassicasterol and epibrassicasterol in the chromophycota. Comparative Biochemistry and Physiology B - Biochemistry and Molecular Biology, 97: 491-494

Goad, L.J. (1981). Sterol biosynthesis and metabolism in marine invertebrates. Pure and Applied Chemistry, 53: 837-852.

GoAd, L.J., Holz, G.G. \& BEACH, D.H. (1983). Identification of (24S)-24-methylcholesta-5,22-dien-3-beta-ol as the major sterol of a marine cryptophyte and a marine prymnesiophyte. Phytochemistry, 22: 475-476.

Gordillo, F.J.L., Jimenez, C., Goutx, M. \& Niell, X. (2001). Effects of $\mathrm{CO}_{2}$ and nitrogen supply on the biochemical composition of Ulva rigida with especial emphasis on lipid class analysis. Journal of Plant Physiology, 158: 367-373.

Grandmougin-Ferjani, A., Schuler-Muller, I. \& Hartmann, M.A. (1997). Sterol modulation of the plasma membrane 
$\mathrm{H}^{+}$-ATPase activity from corn roots reconstituted into soybean lipids. Plant Physiology, 113: 163-174.

GrieneISEN, M.L. (1994). Recent advances in our knowledge of ecdysteroid biosynthesis in insects and crustaceans. Insect Biochemistry and Molecular Biology, 24: 115-132.

Guschina, I.A. \& Harwood, J.L. (2009). Algal lipids and effect of the environment on their biochemistry. In Lipids in Aquatic Ecosystems (Arts, M.T., Brett, M.T. \& Kainz, M.J., editors), 1-24. Springer, New York.

Hartmann, M.A. (1998). Plant sterols and the membrane environment. Trends in Plant Science, 3: 170-175.

Hartmann, M.A. (2004). Sterol metabolism and functions in higher plants. In Lipid Metabolism and Membrane Biogenesis (Daum, G., editor), 57-81. Springer, Berlin.

Havaux, M. (1998). Carotenoids as membrane stabilizers in chloroplasts. Trends in Plant Science, 3: 147-151.

Horváth, G., Melis, A., Hideg, É., Droppa, M. \& Vigh, L. (1987). Role of lipids in the organization and function of photosystem II studied by homogeneous catalytic hydrogenation of thylakoid membranes in situ. Biochimica et Biophysica Acta (BBA) Bioenergetics, 891: 68-74.

Klausmeier, C.A., Litchman, E., Daufresne, T. \& Levin, S.A. (2004). Optimal nitrogen-to-phosphorus stoichiometry of phytoplankton. Nature, 429: 171-174.

Lukas, M., Sperfeld, E. \& Wacker, A. (2011). Growth rate hypothesis does not apply across colimiting conditions: cholesterol limitation affects phosphorus homoeostasis of an aquatic herbivore. Functional Ecology, 25: 1206-1214.

Martin-Creuzburg, D., Sperfeld, E. \& Wacker, A. (2009) Colimitation of a freshwater herbivore by sterols and polyunsaturated fatty acids. Proceedings of the Royal Society of London, B: Biological Sciences, 276: 1805-1814.

Martin-Creuzburg, D. \& von Elert, E. (2009a). Ecological significance of sterols in aquatic food webs. In Lipids in Aquatic Ecosystems (Arts, M.T., Brett, M.T. \& Kainz, M.J., editors), 43-64. Springer, New York.

Martin-Creuzburg, D. \& von Elert, E. (2009b). Good food versus bad food: the role of sterols and polyunsaturated fatty acids in determining growth and reproduction of Daphnia magna. Aquatic Ecology, 43: 943-950.

Martin-Creuzburg, D., Westerlund, S.A. \& Hoffmann, K.H (2007). Ecdysteroid levels in Daphnia magna during a molt cycle: determination by radioimmunoassay (RIA) and liquid chromatography-mass spectrometry (LC-MS). General and Comparative Endocrinology, 151: 66-71.

Mitchell, S.E., Halves, J. \& Lampert, W. (2004). Coexistence of similar genotypes of Daphnia magna in intermittent populations: response to thermal stress. Oikos, 106: 469-478.
Mitchell, S.E. \& LAMPERT, W. (2000). Temperature adaptation in a geographically widespread zooplankter, Daphnia magna. Journal of Evolutionary Biology, 13: 371-382

Mock, T. \& Kroon, B.M.A. (2002). Photosynthetic ener gy conversion under extreme conditions - II: the significance of lipids under light limited growth in Antarctic sea ice diatoms. Phytochemistry, 61: 53-60.

Moreau, R.A., Whitaker, B.D. \& Hicks, K.B. (2002) Phytosterols, phytostanols, and their conjugates in foods: structural diversity, quantitative analysis, and health-promoting uses. Progress in Lipid Research, 41: 457-500.

Nichols, H.W. (1973). Growth media - fresh water. In Handbook of Phycological Methods: - Culture Methods and Growth Measurements (Stein, J.R., editor), 7-24. Cambridge University Press, Cambridge.

Piepho, M., Martin-Creuzburg, D. \& Wacker, A. (2010). Simultaneous effects of light intensity and phosphorus supply on the sterol content of phytoplankton. PLoS ONE, 5: e15828, doi:10.1371/journal.pone.0015828.

Rhee, G.Y. (1978). Effects of N-P atomic ratios and nitrate limitation on algal growth, cell composition, and nitrate uptake. Limnology and Oceanography, 23: 10-25.

Rog, T., Pasenkiewicz-Gierula, M., Vattulainen, I. \& Karttunen, M. (2009). Ordering effects of cholesterol and its analogues. Biochimica et Biophysica Acta - Biomembranes, 1788: $97-121$.

Schuler, I., Milon, A., Nakatani, Y., Ourisson, G., Albrecht, A.M., Benveniste, P. \& Hartmann, M.A. (1991). Differential effects of plant sterols on water permeability and on acyl chain ordering of soybean phosphatidylcholine bilayers. Proceedings of the National Academy of Sciences USA, 88: 6926-6930.

SPERFELD, E. \& WACKER, A. (2009). Effects of temperature and dietary sterol availability on growth and cholesterol allocation of the aquatic keystone species Daphnia. Journal of Experimental Biology, 212: 3051-3059. .

Sperfeld, E., Martin-Creuzburg, D. \& Wacker, A. (2012). Multiple resource limitation theory applied to herbivorous consumers: Liebig's minimum rule versus interactive co-limitation. Ecology Letters, 15: 142-150.

Tranvik, L.J., Porter, K.G. \& Sieburth, J.M. (1989). Occurrence of bacterivory in Cryptomonas, a common fresh-water phytoplankter. Oecologia, 78: 473-476.

Volkman, J.K. (2003). Sterols in microorganisms. Applied Microbiology and Biotechnology, 60: 495-506.

Wacker, A. \& Martin-Creuzburg, D. (2007). Allocation of essential lipids in Daphnia magna during exposure to poor food quality. Functional Ecology, 21: 738-747. 